\title{
An Overview of Current Recommendations and Options for the Management of Cancer Pain: A Comprehensive Review
}

\author{
Kyle L. Gress (1) - Karina Charipova · Alan D. Kaye · Omar Viswanath · \\ Ivan Urits
}

Received: August 4, 2020 / Published online: September 7, 2020

(C) The Author(s) 2020

\begin{abstract}
It is estimated that one-third of oncologic patients in the USA do not receive analgesia proportional to or adequate for the intensity of their pain. A mechanism-based approach to oncologic pain therapy is critical to ensure that analgesia regimens are individualized and effective. Since the mechanisms that lead to cancer pain are complex, healthcare providers must be willing to elicit and recognize the symptoms of each individual patient since these factors influence both the experience of pain
\end{abstract}

Digital Features To view digital features for this article go to https://doi.org/10.6084/m9.figshare.12860123.

K. L. Gress $(\bowtie) \cdot$ K. Charipova

Georgetown University School of Medicine,

Washington, DC, USA

e-mail: klg93@georgetown.edu

A. D. Kaye · O. Viswanath

Department of Anesthesiology, Louisiana State

University Health Shreveport, Shreveport, LA, USA

O. Viswanath

Department of Anesthesiology, Creighton

University School of Medicine, Omaha, NE, USA and response to treatment. This process is centered on the use of detailed history in order to understand symptom expression in the context of primary tumor diagnosis and progression, history of cancer pain, psychological distress, sleep disturbances, cognitive function, and addictive behavior. Incorporating all of these factors into the assessment of a patient's pain condition can facilitate management decisions and help predict patient response to treatment.

Keywords: Cancer pain; Chronic pain; Neoplasms; Opioids; Pain management

O. Viswanath

Valley Pain Consultants-Envision Physician

Services, Phoenix, AZ, USA

O. Viswanath

Department of Anesthesiology, University of

Arizona College of Medicine-Phoenix, Phoenix, AZ, USA

I. Urits

Department of Anesthesiology, Critical Care, and

Pain Medicine, Beth Israel Deaconess Medical

Center, Harvard Medical School, Boston, MA, USA 


\section{Key Summary Points}

While the prevalence of cancer is increasing secondary, in part due to the advent of new diagnostic techniques, the incidence of cancer pain does not seem to be decreasing despite progress in the development of targeted cancer therapies.

Assessments of cancer pain must be multifactorial and patient-centered; treatment is largely dependent on pharmacotherapy.

Future research should utilize patientreported outcome measurements to drive the improvement of assessment tools and the development of new treatment options for the management of cancer pain, including neuraxial anesthesia and neuroablative techniques.

\section{DIGITAL FEATURES}

This article is published with digital features to facilitate understanding of the article. To view digital features for this article go to https://doi. org/10.6084/m9.figshare.12860123.

\section{INTRODUCTION}

Pain is one of the most common symptoms endorsed by cancer patients, especially those with metastatic disease [1]. Pain associated with oncologic disease negatively impacts the quality of life and, in many instances, serves as the clinical representation of tumor progression [1]. In addition to physical manifestations, cancer pain has psychosocial effects, including include anxiety and depression [2]. Cancer pain can be acute or chronic, and its subclassification dictates treatment [1]. Over the last 25 years, significant advances have been made in the fields of oncology and pain management, but the incorporation of this information into clinical practice is lagging [3]. Despite increased recognition of cancer pain and widespread adoption of clinical recommendations for its management, adequate and consistent pain relief continues to be difficult to achieve in patients with oncologic disease $[4,5]$. Inadequate management is most prevalent in children, members of underserved communities and impoverished countries, geriatric patients, and outpatients with metastatic progression of disease [6-9]. Factors contributing to the undertreatment of cancer pain include fear of overprescribing, lack of knowledge concerning adequate treatment, and patient hesitations regarding the use of opioids [10, 11].

This article is based on previously conducted studies and does not contain any studies with human participants or animals performed by any of the authors.

\section{ETIOLOGY}

Chronic cancer-related pain is subclassified in the International Classification of Diseases 11th Revision (ICD-11) as chronic cancer pain and chronic post-cancer treatment pain [12]. Chronic cancer pain is inflammatory or neuropathic pain that is a direct effect of the primary cancer or cancer metastases while chronic postcancer treatment pain refers to painful sequellae from treatment interventions [12]. Both the 2014 and 2020 World Cancer Reports illustrate that vast improvements in treatments for more than a decade have enabled increased survival in those diagnosed with cancer; however, these improvements have also increased the incidence of chronic cancer-related pain in survivors as the development of pain directly increases with increasing number of years lived with cancer $[13,14]$.

The mechanisms for chronic cancer pain vary depending on tumor type and location [15]. The tumor exists in a dynamic relationship with its environment-both secrete mediators that are implicated in angiogenesis and peripheral sensitization $[12,16]$. Both primary and secondary tumors can spread to the bone, leading to pain through several mechanisms, such as structural disruption, inflammatory 
mediator release, and alteration of osteoclast activity [17]. The resulting disruption of the periosteum, marrow, or cortex can result in pain. These mechanisms for cancer pain are most pertinent in patients with metastatic disease, in whom pain occurs most often due to direct tumor infiltration [18].

Treatment-related pain can be due to surgery, chemotherapy, and radiotherapy, among other causes $[12,19]$. The concept of persistent post-surgical pain (PPSP) refers to continued pain lasting at least 2 months following a procedure. PPSP is frequently reported by cancer survivors [20]. It is believed to be caused by pathologic neural plasticity; by definition, it is limited to the territory or dermatome associated with the surgery [21-23]. PPSP is most prevalent in patients who undergo thoracotomy, breast surgery, and limb amputation [23]. Chemotherapy-induced peripheral neuropathy is a form of treatment-related pain that affects the long sensory nerve fibers and is commonly associated with the infusion of platinum compounds, vinca alkaloids, and taxanes [23, 24]. Similarly, antineoplastic treatment with radiotherapy can be a root cause of cancer pain secondary to damage to non-malignant tissue. Radiotherapy-induced pain can be early- or lateonset, with early-onset pain being typical in tissues with high turnover, such as the mucosa, and late-onset pain occurring in nerve and muscle tissue [25]. Recently developed more targeted therapeutic options in both chemotherapy and radiotherapy have the aim to reduce these associated adverse effects.

\section{EPIDEMIOLOGY}

The global prevalence of cancer is increasing secondarily, in part due to significant improvements in the identification and treatment of malignancies. Despite the abundant body of literature on cancer pain, accurate worldwide prevalence data are not available $[13,14,26,27]$. Even in advanced cancer, it is estimated that approximately $70 \%$ of patients with oncologic disease report pain, but prevalence still varies with cancer type and stage [28]. A recently updated meta-analysis calculating prevalence rates for cancer pain in multiple patient subgroups revealed an increasing burden of disease over the past decade $[29,30]$. The working group first published the meta-analysis in 2007, and updated it in 2016, with the results showing pain in: patients after curative treatment (33\% in 2007 vs. $39 \%$ in 2016), patients with advanced disease (64\% in 2007 vs. $66 \%$ in 2016), and patients at all disease stages (53\% in 2007 vs. $51 \%$ in 2016) $[29,30]$. The highest prevalence of cancer pain in this study was found to occur in patients with head and neck disease $[29,30]$.

\section{DIAGNOSIS}

\section{Presentation}

A comprehensive history and physical are important for the assessment of pain in oncology patients. It is crucial to elicit a thorough description of the pain, including classic factors such as location, intensity, character, radiation, duration, timing, and provocative and alleviating factors [31]. Of note, it is not uncommon for oncologic patients to report more than one site of pain and, consequently, it is important that pain in these patients be accurately assessed at every anatomic location, including viscera, bone, and nervous tissue [31]. Although pain is traditionally classified as acute or chronic, the dependence of cancer pain on the progression of the disease and the associated tissue damage makes such a differentiation difficult [31]. Cancer pain can be continuous, commonly described as "background pain;" alternatively canacer pain can be described as intermittent [12]. Intermittent pain, also known as episodic pain, is further subclassified into predictable (incident) pain and unpredictable (spontaneous) pain [12]. Intermittent pain is used to characterize transitory increases, or exacerbations, of pain intensity on a background of chronic, managed pain; for example, with increased weight bearing [12]. At least 50\% of patients with cancer pain experience intermittent pain, which was previously classified as breakthrough pain $[12,32]$. 
For certain types of cancer pain, it has been possible to consolidate clusters of signs and symptoms into specific pain syndromes. These definitions, when used in combinations with individual patient characteristics, can be beneficial in guiding the assessment and selection of treatment. The International Association for the Study of Pain (IASP) Task Force in cancer pain has published a syndromic classification of pain caused directly by solid tumors [12]. Similarly, common pain syndromes in patients with hematologic malignancies have also been defined [12, 33, 34]. The Edmonton Classification System for Cancer Pain (ECS-CP) uses five domains, namely, mechanism of pain, incidental pain, psychologic distress, addictive behavior, and cognitive function, to classify cancer pain [35]. However, despite the ECS-CP being currently considered one of the best tools for defining cancer pain, it is not widely used in clinical practice [31]. To date, there is no universally accepted pain classification measure that can accurately predict the prognosis of pain in oncology patients [36-38].

\section{Evaluation}

Accurate evaluation of cancer pain is essential to characterizing the pain, identifying the underlying mechanism, and guiding decisionmaking with regard to management. Unfortunately, many pain assessments currently used in clinical practice are not beneficial in cancer patients since the diagnosis of cancer has been shown to change the way that patients perceive and communicate pain [39]. Tools that utilize a Likert-type system to evaluate pain intensity do not reflect the complex biopsychosocial nature of cancer pain [40,41]. Assessments that take into account elements of pain beyond severity include the Brief Pain Inventory (BPI) and the McGill Pain Questionnaire (MPQ), both of which have been validated in cancer patients and are available in several languages [42, 43]. The MPQ evaluates pain intensity, visual analogue scale assessment, and pain descriptors but also considers the "affective" aspects of pain [44]. The MPQ-SF, a shortened version of the $\mathrm{MPQ}$, has been updated to make it more effective at detecting neuropathic pain [8]. The $\mathrm{BPI}$, like the MPQ, is divided into an element that evaluates pain severity and one that focuses more on the experience of pain [45]. Despite the development of such new tools for the evaluation of cancer pain, the heterogeneity of its presentation makes it difficult to select a gold standard for assessment. It has been demonstrated that the choice of evaluation tool influences the adequacy of treatment [46]. This outcome highlights the importance that healthcare providers consider the multifactorial nature of cancer pain, and that any discussion about assessment must be patient- and outcome-centered.

\section{Differential Diagnosis}

Not every type of pain experienced by oncology patients is secondary to malignancy. A prospective study of cancer patients determined that approximately $17 \%$ of pain experienced in this subset of patients is secondary to anticancer treatment, while approximately $10 \%$ is secondary to other etiologies that are unrelated to their disease [47].

\section{Prognosis}

While the IASP classification system uses descriptive coding to categorize oncologic pain, it is not helpful at establishing a prognosis. The Cancer Pain Prognostic Scale (CPPS) was developed in an effort to predict the likelihood of achieving pain relief in cancer patients who report moderate to severe cancer pain [48]. The CPPS uses a predictive formula that combines characteristics such as pain severity, pain severity, emotional well-being, and the daily opioid requirement to assign each patient a score ranging from 0 to 17 [48]. Higher scores on the CPPS indicate a higher probability of pain relief [48].

\section{TREATMENT AND MANAGEMENT}

It is generally agreed that a comprehensive approach to the treatment of cancer pain that includes both pharmacologic and non- 
pharmacologic modalities should be the standard of care [49]. Options that are non-pharmacologic include interventional procedures, physical therapy, occupational therapy, and behavioral medicine treatments. The usefulness of behavioral medicine treatment underscores the concept that the pain experience is affected by not only tissue injury but also by psychological and social factors, such as anxiety, catastrophizing, and somatization [50]. Behavioral medicine encompasses treatments such as cognitive behavioral therapy, stress management, and relaxation imagery [50]. Methods such as acupuncture and massage may be useful but have varying degrees of evidence-based support [51].

In 1986, the World Health Organization (WHO) proposed a pain ladder as a stepwise approach to analgesia for cancer pain [52]. The ladder describes non-opioid medications as the first line treatment, followed by weak opioids and, subsequently, strong opioids [52]. While morphine was historically the gold standard for opioid treatment of cancer pain, it has been replaced with newer semi-synthetic opioids, such as oxycodone and hydrocodone, in updated treatment guidelines; however, the core notion of the pain ladder is still followed [53-55]. To date, no difference has been demonstrated in the efficacies of morphine, oxycodone, and hydrocodone as options for third-step treatment [53]. The WHO ladder recommendations can also be manipulated depending on the underlying cause of pain, as shown by recent treatment guidelines [53-55]. Osteogenic pain from bony metastasis can benefit from treatment with nonsteroidal antiinflammatory drugs, while neuropathic pain can be targeted with anticonvulsant and antidepressant medications [49]. Of note, guidelines recommend treating breakthrough pain with rapid- or short-acting opioids with rescue doses to avoid end-of-dose failure [54-57].

While the WHO pain ladder and the treatment guidelines described above provide a stepwise algorithm for escalating opioid doses, they do not account for cases in which analgesia is not achieved despite high doses or cases of intolerable side effects [58]. Interventional procedures for cancer pain include neuroablative procedures, soft tissue injections, and neuraxial analgesia [59, 60]. For example, the approach to PPSP involves the use of local anesthetic infiltration by an indwelling central or peripheral nerve catheter [20]. These methods are frequently cited in the literature, but randomized controlled trials are lacking, hence their absence in current recommendations. Future research is warranted; however, currently barriers to treatment include a large difference in cost and increased risk of side effects.

\section{Complications}

Opioids currently serve as the foundation for medical management of moderate to severe cancer pain [18]. As such, side effects from opioid use are a common complication of chronic cancer pain treatment. Opioid-related adverse effects include those that are normal and expected, such as nausea, vomiting, and constipation, as well as unexpected reactions that may warrant changes in the pain regimen [61]. Given the large body of literature on opioid side effects, expectations regarding opioid treatment should be reviewed with patients prior to treatment initiation. Avoidable side effects should also be monitored and treated appropriately by healthcare providers. Likewise, in light of the current opioid epidemic, patients should be both screened for substance use disorder prior to initiation of a pain regimen and monitored throughout treatment [61].

\section{Patient Education}

Patient education is essential for planning treatment that maximizes opportunities for the adequate alleviation of pain. While effective treatment of cancer pain hinges on pharmacotherapy, barriers to sufficient pain control using medication include underreporting of pain, fear of analgesics (such as opioids), and fear of the association between pain and disease progression [50]. These obstacles are frequently associated with poor compliance and subsequent inadequate pain management [50]. Appropriate patient education allows these 
hindrances to be identified and subsequently overcome for each individual patient [62]. Treatment options such as behavioral medicine represent a non-pharmacologic approach to the management of cancer pain that places great emphasis on education [62]. While research is limited, education supplemented with psychosocial intervention may be helpful in improving outcomes when used in conjunction with pharmacotherapy.

\section{CONCLUSION}

Cancer pain is endorsed by a large portion of oncologic patients at some point in their disease course. While cancer pain most frequently occurs in patients with metastatic progression, the timing and quality of pain are dependent on cancer type and treatment. Although significant progress has been made in the development of techniques for both diagnosis and management of most oncologic conditions, fewer advances have been made in the realm of evaluation and treatment of cancer pain. At present, there is no standardized methodology for the assessment of cancer pain. As such, future studies should focus on creating multifactorial and patient-centered techniques that allow for individualized management.

\section{ACKNOWLEDGEMENTS}

Funding. No funding or sponsorship was received for this study or publication of this article.

Authorship. All named authors meet the International Committee of Medical Journal Editors (ICMJE) criteria for authorship for this article, take responsibility for the integrity of the work as a whole, and have given their approval for this version to be published.

Disclosures. All authors (Kyle L. Gress, Karina Charipova, Alan D. Kaye, Omar Viswanath, and Ivan Urits) have nothing to disclose.
Compliance with Ethics Guidelines. This article is based on previously conducted studies and does not contain any studies with human participants or animals performed by any of the authors.

Open Access. This article is licensed under a Creative Commons Attribution-NonCommercial 4.0 International License, which permits any non-commercial use, sharing, adaptation, distribution and reproduction in any medium or format, as long as you give appropriate credit to the original author(s) and the source, provide a link to the Creative Commons licence, and indicate if changes were made. The images or other third party material in this article are included in the article's Creative Commons licence, unless indicated otherwise in a credit line to the material. If material is not included in the article's Creative Commons licence and your intended use is not permitted by statutory regulation or exceeds the permitted use, you will need to obtain permission directly from the copyright holder. To view a copy of this licence, visit http:// creativecommons.org/licenses/by-nc/4.0/.

\section{REFERENCES}

1. Cherny N. The management of cancer pain. CA Cancer J Clin. 2000;40:70-116.

2. Li X, Xiao W, Yang P, Zhao H. Psychological distress and cancer pain: results froma controlled crosssectional survey in China. Sci Rep. 2017;7(28): 393-7.

3. Breivik H, Cherny N, Collett D, de Conno F, Filbet M, Foubert A. Cancer-related pain: a pan-European survey of prevalence, treatment, and patient attitudes. Ann Oncol. 2009;20:1420-33.

4. World Health Organization. Cancer pain relief. 1986. https://apps.who.int/iris/handle/10665/ 43944. Accessed 5 July 2020.

5. World Health Organization. Cancer pain relief with a guide to opioid availability, 2nd edition. 1996. https://apps.who.int/iris/handle/10665/37896. Accessed 5 July 2020.

6. Bernabei R, Gambassi G, Lapane K, Landi F, Gatsonis C, Dunlop R. Management of pain in elderly patients with cancer. JAMA. 1998;279:1877-82. 
7. Cleeland C, Gonin R, Hatfield A, Edmonson J, Blum R. Pain and its treatment in outpatients with metastatic cancer. N Eng J Med. 1994;330:592-6.

8. Wolfe J, Grier H, Klar N, Levin S, Ellenbogen J, Salem-Schatz S. Symptoms and suffering at the end of life in children with cancer. $\mathrm{N}$ Eng J Med. 2000;342:326-33.

9. Cleeland C, Gonin R, Baez L, Loehrer P, Pandya K. Pain and treatment of pain in minority patients with cancer. Ann Intern Med. 1997;127:813-6.

10. Klepstad P, Kaasa S, Chernyl N, Hanks G, de Conno F. Pain and pain treatments in European palliative care units: a cross-sectional survey from the European Association for Palliative Care Research Network. Palliat Med. 2005;19:477-84.

11. Weiss S, Emanuel L, Fairclough D, Emanuel E. Understanding the experience of pain in terminally ill patients. Lancet. 2001;357:1311-5.

12. Bennett MI, Kaasa S, Barke A, Korwisi B, Rief W, Treede RD. The IASP classification of chronic pain for ICD-11: Chronic postsurgical or posttraumatic pain. Pain. 2019;160(1):45-52.

13. Stewart B, Wild C (eds). World cancer report 2014. Geneva: International Agency for Research on Cancer/World Health Organization. https://www. who.int/cancer/publications/WRC_2014/en/. Accessed 5 July 2020.

14. Wild CP, Weiderpass E, Stewart BW (eds). World cancer report 2020. Geneva: International Agency for Research on Cancer/World Health Organization. https://www.iarc.fr/cards_page/world-cancerreport/. Accessed 5 July 2020.

15. Schmidt B. The neurobiology of cancer pain. J Oral Maxillofac Surg. 2015;73(12):S132-5.

16. Le Bitoux M, Stamenkovic I. Tumour-host interactions: the role of inflammation. Histochem Cell Biol. 2008;130(6):1079-90.

17. Blair J, Zhou H, Seibel M, Dunstan C. Mechanisms of disease: roles of OPG, RANKL, and RANK in the pathophysiology of skeletal metastasis. Nat Clin Pr Oncol. 2006;3(1):41-9.

18. Reis-Pina P, Lawlor P, Barbosa A. Cancer-related pain management and the optimal use of opioids. Acta Med Port. 2015;28:376-81.

19. Jost L. ESMO minimum clinical recommendations for the management of cancer pain. Ann Oncol. $2005 ; 16: 83-5$.
20. Hucker T, Winter N, Chou J. Challenges and advances in pain management for the cancer patient. Curr Anesth Rep. 2015;5:346-53.

21. Humble S, Dalton A, Li L. A systematic review of therapeutic interventions to reduce acute and chronic post-surgical pain after amputation, thoracotomy or mastectomy. Eur J Pain. 2015;19(4): 451-65.

22. Andreae M, Andreae D. Regional anaesthesia to prevent chronic pain after surgery: a Cochrane systematic review and meta-analysis. Br J Anaesth. 2013;111(5):711-20.

23. Magee D, Bachtold S, Brown M, Farquhar-Smith P. Cancer pain: where are we now? Pain Manag. 2019;9(1):63-79.

24. Seretny M, Currie G, Sena E. Incidence, prevalence, and predictors of chemotherapy-induced peripheral neuropathy: a systematic review and meta-analysis. Pain. 2014;155(12):2461-70.

25. Marin A, Martin M, Linan O. Bystander effects and radiotherapy. Rep Pract Oncol Radiother. 2015;20(1):12-21.

26. Glaser A, Fraser L, Corner J. Patient-reported outcomes of cancer survivors in England 1-5 years after diagnosis: a cross-sectional survey. BMJ Open. 2013;3(4):e002317.

27. Elliott J, Staetsky L, Smith P, Foster C, Maher E, Corner J. The health and well-being of cancer survivors in the UK: findings from a population-based survey. Br J Cancer. 2011;105:S11-20.

28. Hearn J, Higginson I. Cancer pain epidemiology: a systematic review. In: Bruera E, Portenoy R, editors. Cancer pain: assessment and management. London: Cambridge University Press; 2003:19-37.

29. Beuken-van Everdingen $M$, de Rijke J, Kessels A, Schouten $H$, van Kleef M, Patijn J. Prevalence of pain in patients with cancer: a systematic review of the past 40 years. Ann Oncol. 2007;18(9):1437-49.

30. Van Den Beuken-Van Everdingen MHJ, Hochstenbach LMJ, Joosten EAJ, Tjan-Heijnen VCG, Janssen DJA. Update on prevalence of pain in patients with cancer: systematic review and meta-analysis. J Pain Symptom Manage. 2016;51(6):1070-1090.e9. https://doi.org/10.1016/j.jpainsymman.2015.12. 340 .

31. Caraceni A, Shkodra M. Cancer pain assessment and classification. Cancers (Basel). 2019;11(4):510.

32. Deandrea S, Corli O, Consonni D, Villani W, Greco M, Apolene G. Prevalence of breakthrough cancer pain: a systematic review and a pooled analysis of 
published literature. J Pain Symptom Manag. 2014;47:57-76.

33. Niscola P, Tendas A, Scaramucci L, et al. Pain in malignant hematology. Expert Rev Hematol. 2011;4:81-93.

34. Niscola P, Cartoni C, Romani C, et al. Epidemiology, features and outcome of pain in patients with advanced hematological malignancies followed in a home care program: an Italian survey. Ann Hematol. 2007;86:671-6.

35. Fainsinger R, Nekolaichuk C. A "TNM" classification system for cancer pain: the Edmonton Classification System for Cancer Pain (ECS-CP) support. Care Cancer. 2008;16:547-55.

36. Fainsinger R, Nekolaichuk C, Lawlor P, Het al. An international multicentre validation study of a pain classification system for cancer patients. Eur J Cancer. 2010;46:2896-904.

37. Knudsen A, Brunelli C, Klepstad P, et al. Which domains should be included in a cancer pain classification system? Pain. 2012;153:696-703.

38. Knudsen A, Brunellil C, Kaasal S, et al. Which variables are associated with pain intensity and treatment response in advanced cancer patients? Eur J Pain 2. 2011;15:320-7.

39. Herr K. Evidence-based assessment of acute pain in older adults: current nursing practices and perceived barriers. Clin J Pain. 2004;20(5):331-40.

40. Capelli G, De Vincenzo R, Addamo A, Bartolozzi F, Braggio N, Scambia G. Which dimensions of healthrelated quality of life are altered in patients attending the different gynecologic oncology health care settings? Cancer. 2002;95(12):2500-7.

41. Korfager I, Essink-Bot M, Mols F, van de Poll-Franse L, Kruitwagen R, van Ballegooijen M. Health-related quality of life in cervical cancer survivors: a population-based survey. Int J Radiat Oncol Biol Phys. 2009;73(5):1501-9.

42. Kumar S. Utilization of brief pain inventory as an assessment tool for pain in patients with cancer: a focused review. Indian J Palliat Care. 2011;17(2): 108-15.

43. Ngamkham S, Vincent C, Finnegan L, Holden J, Wang Z, Wilkie D. The McGill Pain Questionnaire as a multidimensional measure in people with cancer: an integrative review. Pain Manag Nurs. 2012;13(1):27-51.

44. Dworkin R, Turk D, Revicki D. Development and initial validation of an expanded and revised version of the Short-form McGill Pain Questionnaire (SF-MPQ-2). Pain. 2009;144(1-2):35-42.

45. Cleeland C, Ryan K. Pain assessment: global use of the Brief Pain Inventory. Ann Acad Med Singapore. 1994;23(2):129-38.

46. de Wit R, van Dam F, Abu-Saad H. Empirical comparison of commonly used measures to evaluate pain treatment in cancer patients with chronic pain. J Clin Oncol. 2010;17(4):1280.

47. Grond S, Zech D, Diefenbach C, Radbruch L, Lehmann K. Assessment of cancer pain: a prospective evaluation in 2266 cancer patients referred to a pain service. Pain. 1996;64:107-14.

48. Hwang S, Chang V, Fairclough D, Kasimis B. Development of a cancer pain prognostic scale. J Pain Symptom Manag. 2002;24:366-78.

49. Portenoy R. Treatment of cancer pain. Lancet. 2011;377:2236-47.

50. Liu W, Zheng Z, Tan K, Meredith G. Multidimensional treatment of cancer pain. Curr Oncol Rep. 2017;19AD:10.

51. $\mathrm{Hu} \mathrm{C}$, Zhang $\mathrm{H}, \mathrm{Wu} \mathrm{W}$, et al. Acupuncture for pain management in cancer: a systematic review and meta-analysis. Evid Based Complement Altern Med. 2016;2016:202-39.

52. Anekar AA, Cascella M. WHO Analgesic Ladder. In: StatPearls. Treasure Island (FL): StatPearls Publishing; May 17, 2020.

53. Caraceni A, Hanks G, Kaasa S. Use of opioid analgesics in the treatment of cancer pain: evidencebased recommendations from the EAPC. Lancet Oncol. 2012;13(2):e58-68.

54. Dowell D, Haegerich TM, Chou R. CDC guideline for prescribing opioids for chronic pain-United States, 2016. JAMA J Am Med Assoc. 2016;315(15): $1624-45$.

55. The Pain Management Best Practices Inter-Agency Task Force-US Department of Health and Human Services. Pain management best practices interagency task force report: updates, gaps, inconsistencies, and recommendations. 2019. https://www. hhs.gov/sites/default/files/pmtf-final-report-201905-23.pdf. Accessed 5 July 2020.

56. Caraceni A, Davies A, Poulain P, Cortes-Funes H, Panchal S, Fanelli G. Guidelines for the management of breakthrough pain in patients with cancer. J Natl Compr Cancer Netw. 2013;11:S29-36.

57. Fallon M, Giusti R, Aielli F, et al. ESMO guidelines committee management of cancer pain in adult 
patients: ESMO clinical practice guidelines. Ann Oncol. 2018;29:iv166-91.

58. Miguel R. Interventional treatment of cancer pain: the fourth step in the World Health Organization analgesic ladder? Cancer Control. 2000;7(2): 149-56.

59. Vayne-Bossert P, Afsharimani B, Good P, Gray P, Hardy J. Interventional options fro the management of refractory cancer pain-what is the evidence? Support Care Cancer. 2016;24(3):1429-38.

60. Urits I, Jones MR, Orhurhu V, et al. A comprehensive review of the celiac plexus block for the management of chronic abdominal pain. Vol. 24, current pain and headache reports, vol. 24. Berlin: Springer; 2020.
61. Scarborough B, Smith C. Optimal pain management for patients with cancer in the modern era. CA Cancer J Clin. 2018;1:35-50.

62. Gunnarsdottir S, Donovan H, Serlin R, Voge C, Ward S. Patient-related barriers to pain management: the barriers questionnaire II (BQ-II). Pain. 2002;99(3):385-96. 